\title{
The art of video games
}

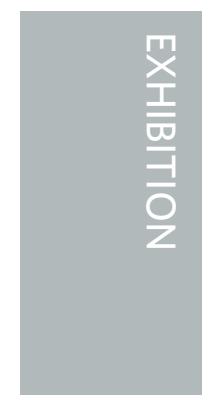

In the past fifteen years or so, technological innovations have transformed the video game industry and made video games a creative platform for engineers, artists and players alike. Today, the industry is a multibilliondollar market with over two billion consumers around the globe. Gamers are able to immerse themselves in alternative realities through cinematic-like scenes, which are often a well-executed blend of cutting-edge technology and art. Videogames: Design/ Play/Disrupt, an exhibition at the Victoria and Albert Museum in London, sets out to examine video games - rightfully — as objects of digital art and to explore themes such as their design process, the impact they have on society, and the gamer community.

The exhibition begins by documenting the stages of development of games from both established companies, such as Nintendo and Sony, and independent developers. One of these games is The Last of Us. Set in a post-apocalyptic United States, it follows Ellie, a young girl trying to survive. On display are character sketches, hand-written sticky notes representing the video sequences, and the lines of code that translate these concepts into highquality graphics. Ellie, however, is not your average character who repeats the same set of instructions each time: she has been programmed with artificial intelligence so that she can react to her surroundings during the game. Embedding such code into the design can reduce the predictability of the game's storyline, making it more realistic and providing a better experience for the players. To make the visuals more convincing, the movements of the characters were adopted from human actors using a motion capture suit, which is included here as part of the installation. The suit is covered with reflective markers so that the motion of the person wearing it can be optically tracked by a camera.

There are also a range of other innovative approaches currently being used to create better game environments. For example, No Man's Sky, a game in which players fly spaceships to different planets, is based on procedural generation instead of sets of sequences. This technique uses algorithms

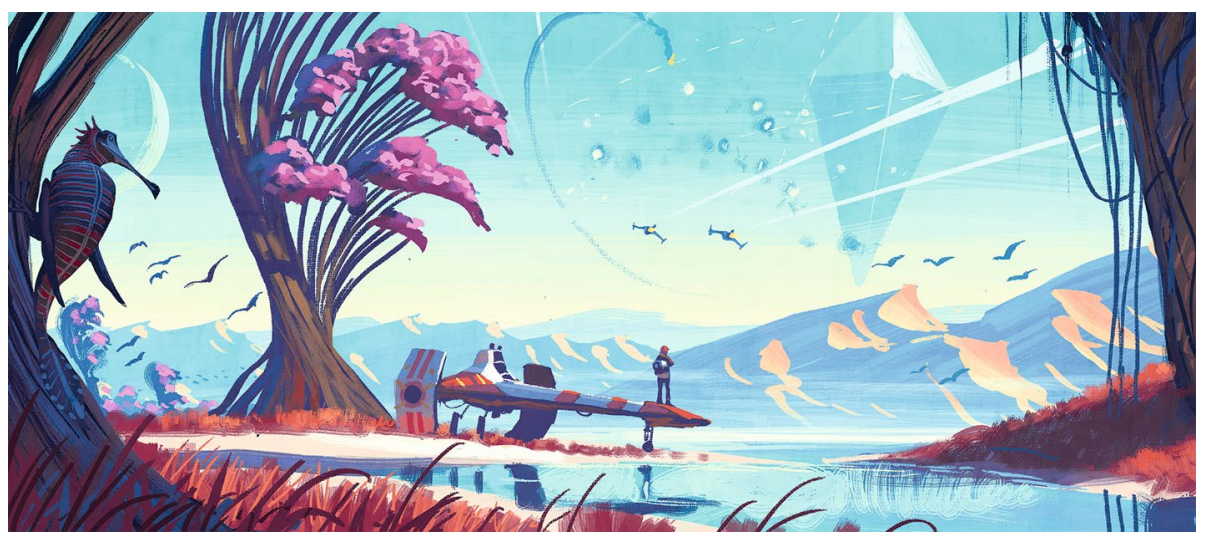

Screenshot from No Man's Sky. Credit: TM/(C) 2016 Hello Games Ltd. Developed by Hello Games Ltd. All rights reserved

to create complex graphics, which depend on the player's actions, from only some basic elements provided by the human designers. As a result, players have quintillions of algorithm-generated planets - each containing algorithm-generated animals, plants and buildings - to explore. The game is a testament to the technological achievements of the past decade and the innovative tools available to developers.

The exhibition also explores how video games can be a disruptive force in the digital age. For some developers, they can become a tool for highlighting ethical or social issues and challenging stereotypes. Such is the case with Phone Story, which was developed in 2011 and removed from the Apple App Store a few days after its release. The game invites players to be part of a phone's life cycle, initiating a discussion about the negative effects of its supply chain on workers around the world.

The next room is dedicated to the online gaming community, which has become a world in which millions of players collaborate, design and compete. A huge screen shows a short clip of the moment a team of five players wins the League of Legends championship, an international video game tournament, to the cheers of a stadium full of people. eSports (or electronic sports) such as this are now professional competitions that are hugely popular around the globe and are expected to grow further in the coming years.

The last section of the exhibition resembles a more traditional video game arcade, where people gather to play games offline. The displays in this section are devoted to games made from repurposed objects by hacker creators, and are often unconventional. For these DIY inventions, anything can become an input controller. The exhibition, for example, displays a photograph of Roflpillar, a game in which players dress as caterpillars and try to collect apples shown on a monitor. The idea is fairly simple: players have to wriggle on the floor to steer the caterpillars by rolling left and right in their caterpillar bags, which are connected to a motion tracker. Here, computer-generated graphics and sophisticated storylines are limited, but the human imagination can easily take over and create the game's environment.

While the popularity of this punk game scene is on the up, it is unlikely that the future of video games is in DIY ideas. Artificial intelligence is an increasingly dominant force in video game design, and the underlying machine-learning techniques are advancing rapidly. Where this will lead video game design in the next 15 years or so will be fascinating to watch.

\section{Reviewed by Christiana Varnava} Videogames: Design/Play/Disrupt runs until 24 February 2019 at the Victoria and Albert Museum, London.

Published online: 12 October 2018 https://doi.org/10.1038/s41928-018-0151-8 